\title{
The oxytocinergic system in PTSD following traumatic childbirth: endogenous and exogenous oxytocin in the peripartum period
}

\author{
A. B. Witteveen ${ }^{1}$ (I) - C. A. I. Stramrood ${ }^{2}$ - J. Henrichs ${ }^{1}$ • J. C. Flanagan ${ }^{3} \cdot$ M. G. van Pampus $^{4} \cdot$ M. Olff ${ }^{5,6}$
}

Received: 18 March 2019 / Accepted: 22 July 2019 / Published online: 6 August 2019

(C) The Author(s) 2019

\begin{abstract}
Birth experiences can be traumatic and may give rise to PTSD following childbirth (PTSD-FC). Peripartum neurobiological alterations in the oxytocinergic system are highly relevant for postpartum maternal behavioral and affective adaptions like bonding and lactation but are also implicated in the response to traumatic events. Animal models demonstrated that peripartum stress impairs beneficial maternal postpartum behavior. Early postpartum activation of the oxytocinergic system may, however, reverse these effects and thereby prevent adverse long-term consequences for both mother and infant. In this narrative review, we discuss the impact of trauma and PTSD-FC on normal endogenous oxytocinergic system fluctuations in the peripartum period. We also specifically focus on the potential of exogenous oxytocin (OT) to prevent and treat PTSD-FC. No trials of exogenous OT after traumatic childbirth and PTSD-FC were available. Evidence from non-obstetric PTSD samples and from postpartum healthy or depressed samples implies restorative functional neuroanatomic and psychological effects of exogenous OT such as improved PTSD symptoms and better mother-to-infant bonding, decreased limbic activation, and restored responsiveness in dopaminergic reward regions. Adverse effects of intranasal OT on mood and the increased fear processing and reduced top-down control over amygdala activation in women with acute trauma exposure or postpartum depression, however, warrant cautionary use of intranasal OT. Observational and experimental studies into the role of the endogenous and exogenous oxytocinergic system in PTSD-FC are needed and should explore individual and situational circumstances, including level of acute distress, intrapartum exogenous OT exposure, or history of childhood trauma.
\end{abstract}

Keywords PTSD $\cdot$ Trauma $\cdot$ Childbirth $\cdot$ Functional neuroanatomical $\cdot$ Psychological $\cdot$ Oxytocin

A. B. Witteveen

a.witteveen@vumc.nl

C. A. I. Stramrood

info@drstramrood.nl

J. Henrichs

j.henrichs@vumc.nl

J. C. Flanagan

Hellmuth@musc.edu

M. G. van Pampus

m.g.vanpampus@olvg.nl

M. Olff

m.olff@amc.uva.nl
1 Department of Midwifery Science/AVAG, Amsterdam Public Health research institute, Amsterdam UMC, location VUmc, Van der Boechorststraat 7, P.O. Box 7057, 1007

MB Amsterdam, The Netherlands

2 Department of Obstetrics and Gynaecology, Amsterdam UMC, location AMC, Meibergdreef 9, Amsterdam 1105 AZ, The Netherlands

3 Department of Psychiatry and Behavioral Sciences, Medical University of South Carolina, 67 President St.,

Charleston 29425, SC, USA

4 Department of Obstetrics and Gynaecology, OLVG, Oosterpark 9, Amsterdam 1091 AC, The Netherlands

5 Department of Psychiatry, Amsterdam UMC, location AMC, Meibergdreef 9, Amsterdam 1105 AZ, The Netherlands

6 Arq Psychotrauma Expert Group, Nienoord 5, Diemen 1112 XE, The Netherlands 


\section{Introduction}

The observation that women may develop posttraumatic stress disorder following childbirth (PTSD-FC; DSM-5 American Psychiatric Association 2013) emerged only two decades ago (Ballard et al. 1995) and has gained increasing attention ever since (Grekin and O'Hara 2014; National Institute for Clinical Excellence 2014). PTSD-FC may develop when mothers or their partners experienced or witnessed an actual or threatened death or serious injury of the newborn or mother (American Psychiatric Association 2013). PTSD is characterized by persistent symptoms of re-experiencing traumatic events, avoidance of distressing trauma-related stimuli, negative alterations in cognitions and mood, and hyperarousal (American Psychiatric Association 2013). Prevalence rates of traumatic childbirth vary from 9 to $20 \%$ depending on the exact wording of the A criterion of PTSD (according to DSM-IV or DSM 5) (Ayers et al. 2009; Stramrood et al. 2012; Boorman et al. 2014). In community samples 3-4\% and in high risk samples $16-$ $19 \%$ of women (i.e., with maternal psychiatric history and/or obstetric morbidity) develop PTSD-FC (Grekin and O'Hara 2014; Yildiz et al. 2016). The risk of PTSD-FC increases when peripartum vulnerability factors, such as fear of childbirth, severe health complications, operative delivery, and comorbid depression, are present (Grekin and O'Hara 2014; Koen et al. 2016; König et al. 2016; Ayers et al. 2016). PTSD-FC has a negative impact on family relationships, parent-to-infant bonding, future family planning, and subsequent infant development (McDonald et al. 2011; Parfitt and Ayers 2014; Cook et al. 2018).

Rigorous research on interventions to prevent PTSD-FC is however lacking, despite its clear need (McKenzie-McHarg et al. 2015). Although randomized clinical trials (RCTs) have been undertaken to evaluate whether early interventions in women after (traumatic) childbirth prevent the development of PTSD-FC and/or its severity, the majority of trials in unselected postpartum women have been found ineffective (de Graaff et al. 2018). Results from early interventions are more promising in high-risk women such those having experienced emergency caesarian section (Horsch et al. 2017). Furthermore, evidence-based treatments for PTSD, cognitive-behavioral therapy (CBT), and eye movement desensitization reprocessing (EMDR) therapy (National Institute for Clinical Excellence, 2014) have scarcely been evaluated in women with PTSD-FC. A few case studies suggest potential effectiveness of CBT and EMDR to treat PTSD-FC (Ayers et al. 2007; Sandström et al. 2008; Stramrood et al. 2012) and a recent RCT showed that CBT compared with a waitlist control group significantly reduced PTSD-FC symptoms although to a similar extent as the wait-list group (Nieminen et al. 2017). This is not surprising since in the general population already up to one-third of PTSD patients does not benefit from these evidence-based psychological treatments (Bradley et al. 2005; Schottenbauer et al. 2008; Cloitre 2009) and specific preventive or curative interventions may be needed for these target groups (Baas et al. 2017).

Interestingly, add-on medications or hormones have been implicated to enhance treatment response in PTSD in nonobstetric populations (Dunlop et al. 2012). Synthetic hormones like cortisol and oxytocin involved in animal and human stress responses have gained attention in prevention and treatment of PTSD (Koch et al. 2014; Sijbrandij et al. 2015; van Zuiden et al. 2017; Garcia and Delahanty 2017; Birur et al. 2017) and in mothers with postpartum depression and attachment difficulties (Riem et al. 2012; BakermansKranenburg and van IJzendoorn 2013; Kim et al. 2014). Oxytocin may potentially impact the aberrant activity in a neurocircuitry involved in emotional and cognitive processing found in non-obstetric PTSD samples (Sherin and Nemeroff 2011; Zoladz and Diamond 2013; Koch et al. 2014) such as hyperresponsiveness of the amygdala to fearful stimuli reflected in heightened arousal and vigilance seen in PTSD (Shin et al. 2005; Protopopescu et al. 2005). Furthermore, decreased activity of the medial prefrontal cortex (PFC) and diminished structural and functional connectivity between the PFC and amygdala reflect inadequate top-down control over the hyperresponsive amygdala, clarifying the lack of suppression of attention to trauma-related stimuli and the diminished fear-inhibition and extinction in PTSD (Liberzon and Sripada 2008; Zoladz and Diamond 2013; Koch et al. 2014). This lack of top-down control of the mPFC over the amygdala might however be reversed through successful psychotherapeutic PTSD treatment with (adjunct) medications or hormones (Quidé et al. 2012).

Around birth, neuroendocrine interactions between the oxytocinergic system, the hypothalamus-pituitary-adrenal (HPA) axis, and the dopaminergic system are highly relevant for lactation and bonding, for protection against potential threats, for buffering the stress response, and for the motivation to raise offspring (Love 2014; MacDonald and Feifel 2014; Cox et al. 2015). Findings from studies in rats indicate that maternal postpartum behavior negatively affected by peripartum stress can be successfully targeted by early postpartum activation of the oxytocinergic system (with an oxytocin receptor agonist) thereby limiting the adverse life-long consequences of perinatal stress for both infant and mother (Maccari et al. 2014; Gatta et al. 2018). Because the oxytocinergic system is implicated in both PTSD and the peripartum period, we set out a narrative review to discuss the theoretical and empirical basis for the impact of oxytocin on women traumatized following childbirth. Findings from salient research papers on the therapeutic potential of exogenous oxytocin will be reviewed thereby highlighting areas for further research in clinical and neurobiological aspects of PTSD-FC. 


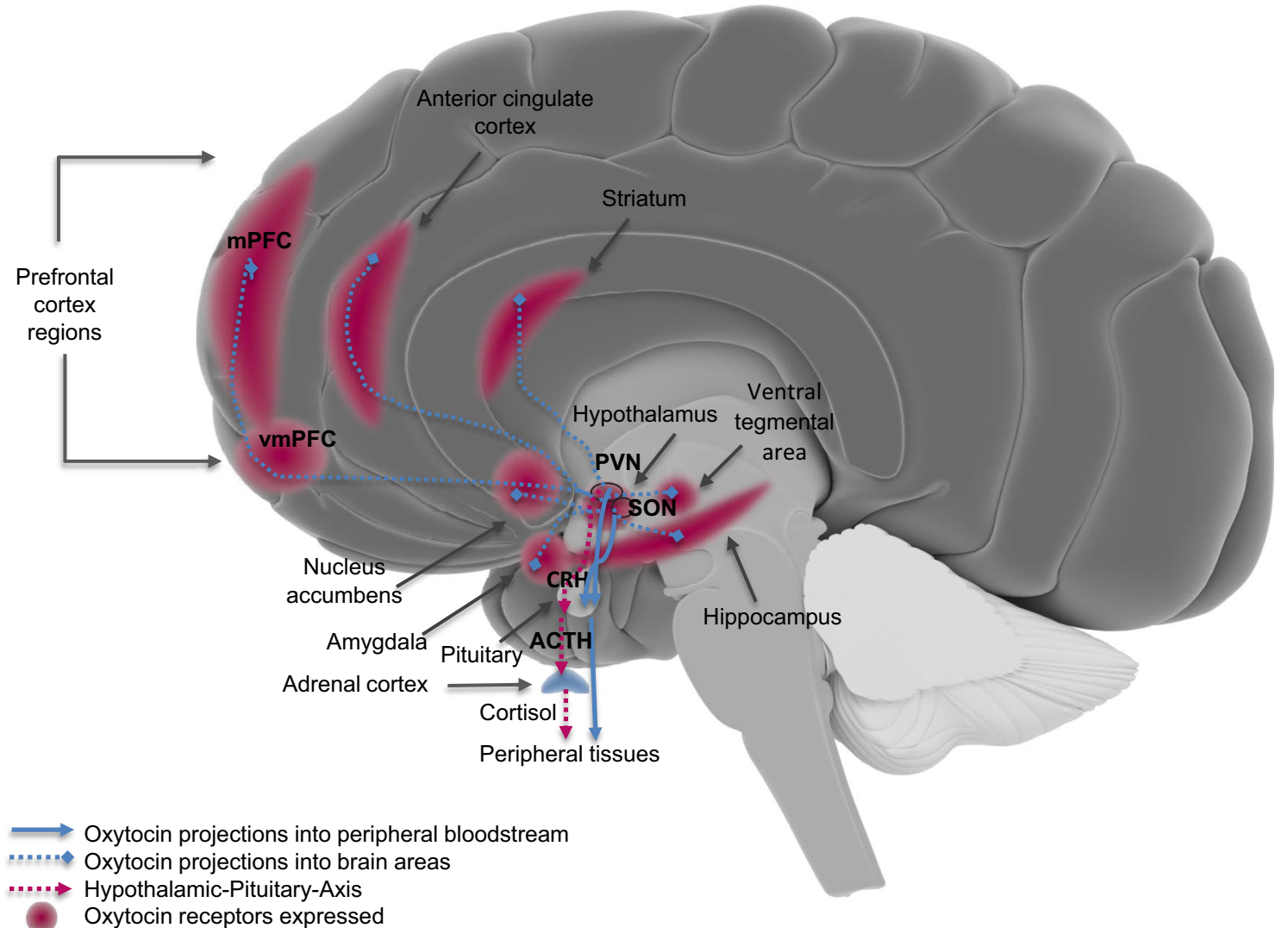

Fig. 1 Simplified schematic representation of oxytocinergic projections to mid- and frontal brain areas and the hypothalamic-pituitary axis (based on animal and human models). PVN, paraventricular nucleus; SON,

\section{The oxytocinergic system in the peripartum period}

The neuropeptide oxytocin (OT) is synthesized in the hypothalamic periventricular and supraoptic nuclei (PVN and SON) and projected to the pituitary gland from where it is released into the peripheral bloodstream (Fig. 1). OT is also centrally released from hypothalamic neurons that directly project into cerebral mid- and frontal regions (such as (pre)frontal cortices and amygdala) (Meyer-Lindenberg et al. 2011; AcevedoRodriguez et al. 2015). Peripheral and central oxytocinergic actions are induced by OT binding to oxytocin receptors (OTRs) that are highly available in the uterus, particularly at the start of labor. For central actions, OTRs are highly available in limbic areas like the amygdala and hippocampus that are also implicated in the traumatic stress response and PTSD (Brunton et al. 2012; Bell et al. 2014) (Fig. 1). OT interacts with the HPAaxis system to buffer the stress response and with dopamine release from the mesolimbic (reward) system directing motivational behavior to approach and engage in social activities (Skuse and Gallagher 2009; Smith and Wang 2012). There are several findings that support these interactions, such as the synaptic contacts between oxytocin- and corticotropinreleasing hormone $(\mathrm{CRH})$-expressing neurons found in the supraoptic nucleus; CRH, corticotropin-releasing-hormone; $\mathrm{ACTH}$, adreno-cortico-tropic-hormone; (v)mPFC, (ventro)medial prefrontal cortex

PVN of rats (Dabrowska et al. 2011) and OTRs found in key areas of the mesocorticolimbic system, such as the ventral tegmental area and nucleus accumbens of rodents that influence motivated behavior (Love 2014).

Around childbirth, OT mRNA expression and OTRs in the hypothalamic nuclei are significantly increased as shown in studies of rodents (Hillerer et al. 2014). OT neurons in the hypothalamus that project to parts of the limbic system such as the amygdala that interconnects with the mPFC show increased dendritic branching and synaptic alterations indicating great plasticity of the maternal brain in this period (Hillerer et al. 2014; Kim and Strathearn 2016). Immediately after birth, hypothalamus-induced neuroendocrine alterations support maternal behavioral adaptation through interactions with the mesocorticolimbic dopamine system, important for motivating behavior and attention directed towards the offspring (Kim and Strathearn 2016). These OT interactions with the dopaminergic mesolimbic system determine and regulate the maternal "reward" gained from raising an offspring as shown in several experimental studies of rats and mice (Olazábal 2018). In humans, maternal peripheral OT levels and attachment quality have been found associated with activity in reward-related functional neuroanatomic areas, such as the striatum, insula, and nucleus accumbens (Strathearn et al. 2009). 
Evidence from preclinical research in rats shows that activity of the OTRs within the medial PFC plays a role in modulation of maternal care and reduction in postpartum anxiety-like behavior and illustrates the relevance of this brain area in the postpartum period and potentially in PTSD-FC (Sabihi et al. 2014). Blockage of OTRs within the medial PFC of rats prevents the normal attenuation of maternal anxiety and increases maternal aggressive behavior (Sabihi et al. 2014). In human studies, higher ante- or postpartum endogenous OT levels have been found associated with positive maternal caregiving behavior, mother-infant bonding, and maternal attachment behavior, particularly in women with more psychosocial stress and anxiety (Strathearn et al. 2012; Zelkowitz et al. 2014; Samuel et al. 2015). However, the normal association between higher peripartum endogenous OT secretion and positive parenting was found disrupted in mothers with adverse childhood experiences (Julian et al. 2018). Furthermore, studies in rats have shown that acute or chronic psychological stress in the perinatal period may hinder the normal adaptive changes in neural plasticity such as the increase of OT mRNA expression and OTRs in the hypothalamus, resulting in a reduction of OTR bindings in relevant brain areas such as the amygdala (Hillerer et al. 2011; Kim and Strathearn 2016). Recently, dysfunctional interactions between the oxytocinergic and dopamine systems have been thought to be involved in mood and postpartum depression (Post and Leuner 2018).

\section{Endogenous and exogenous OT in trauma and PTSD}

After trauma exposure, women generally show higher endogenous OT levels (Seng et al. 2013; Olff et al. 2013) while lower levels have been found in traumatized men (Cao et al. 2014; Frijling et al. 2015). Higher endogenous OT levels in women suggest a necessity to decrease stress reactivity and may indicate an adaptive biological mechanism that motivates social contact-seeking in order to reduce interpersonal distress and conflict (Taylor et al. 2000; Bartz et al. 2011). This is in line with higher OT levels found in trauma-exposed women that were associated with cooperativeness and seeking social support (Nishi et al. 2015). Peripheral OT levels can be increased by affiliation or by exogenous administration and this may have anxiolytic effects (Taylor et al. 2006, 2010). For example, positive OT-induced autonomous responses to social stimuli have been found in women (Ditzen et al. 2013), corresponding with the affiliative response to social stressors resulting in higher endogenous OT levels in women (Taylor et al. 2000). However, in contrast to healthy men who show decreased amygdala activation after intranasal OT administration (Kirsch et al. 2005; Domes et al. 2007), healthy women show increased amygdala activation in reaction to threatrelated or emotion-arousing stimuli after OT administration
(Domes et al. 2010; Lischke et al. 2012; Rilling et al. 2014; Feng et al. 2015).

Table 1 provides an overview of neuroanatomic and psychological findings from RCTs published in peer-reviewed journals of intranasal OT administration in trauma-exposed female or mixed samples with or without PTSD. Overall, findings indicate beneficial psycho-physiological effects in samples of female or mixed PTSD patients such as restored sympathetic cardiac tone and a trend of reduced symptoms of PTSD (e.g., avoidance) and depression when added to prolonged exposure (Sack et al. 2017; Flanagan et al. 2018b), increased compassion towards women (Palgi et al. 2016), and improved anhedonic symptoms (i.e., motivation to engage in activities). OT restored neural responsiveness in regions of the reward pathway in trauma-exposed police officers with and without PTSD and the effect of OT on striatal responsiveness was strongest in individuals with higher anhedonia levels (Nawijn et al. 2016). OT administration also significantly improved aberrant functional neural responses to social rewards in mixed PTSD samples, up to the level found in healthy trauma-exposed individuals in the placebo condition (Nawijn et al. 2017). Interestingly, in men but not women with PTSD, OT increased recognition of body motions of anger (Palgi et al. 2017). This is in line with notion that OT alters the processing of social stimuli such as the salience of interpersonal cues but that behavioral effects depend on the individual and situational aspects (Bartz et al. 2011). For example, OT effects on behavioral performance were modulated by individual differences in sociability with improved performance in women scoring low but decreased performance in women scoring high on agreeableness (Groppe et al. 2013).

An OT-related reduction in amygdala activation in response to social stimuli was found in a mixed sample with PTSD compared with trauma-exposed controls which instead showed enhanced amygdala reactivity to these stimuli after OT (Koch et al. 2016a). OT-related improved connectivity between ventromedial PFC and centromedial amygdala was found in male police officers with PTSD compared with controls (Koch et al. 2016b) while in women with PTSD, connectivity between two areas within a neural circuitry involving parts of the salience network (i.e., amygdala and dorsal anterior cingulate cortex) was increased in the placebo condition but diminished after OT administration (Koch et al. 2016b). The latter suggests anxiolytic effects of OT in this fear circuitry involved in processing of emotions in females.

Taken together, the aforementioned pattern of OT-related reduction PTSD symptoms and improvements of anhedonia and compassion reflected in an increase of reward-related functional activation and reduced amygdala activation indicates enhanced short-term sensitivity for social interactions that are of relevance for involvement and participation in emotionally demanding exposure therapy for PTSD. Recently, these beneficial effects of OT were also found in individuals with PTSD treated with OT 


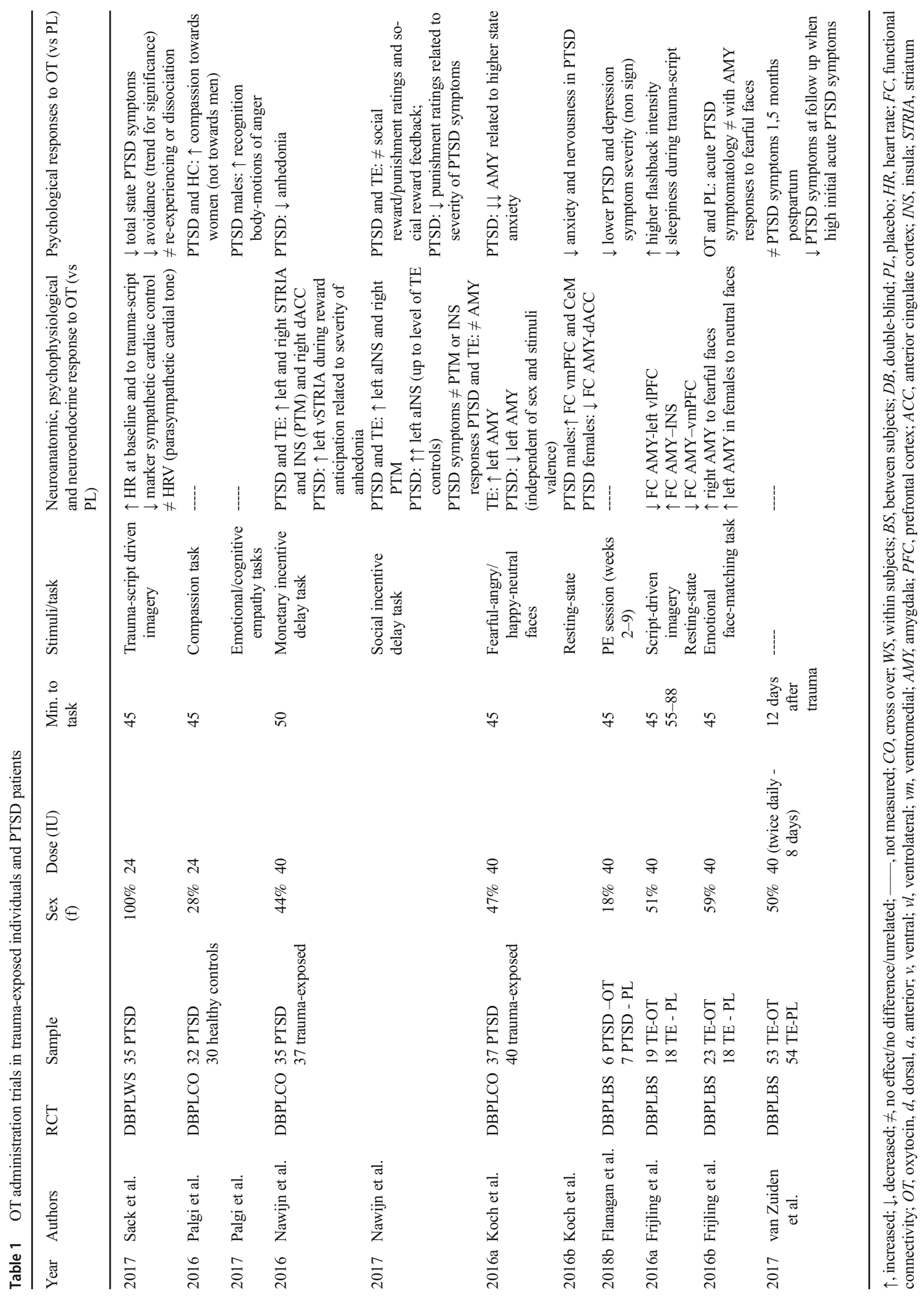


(versus placebo) compared with trauma-exposed controls, as shown by improved working memory scores and enhanced functional connectivity between the dorsolateral PFC and anterior cingulate (Flanagan et al. 2018c).

More negative functional neuroanatomic and psychological effects of intranasal OT were however found in trials among individuals who were recently exposed to trauma such as traffic accidents. Increased fear processing during resting state (Frijling et al. 2016a) and amygdala activation to fearful and neutral faces in females (Frijling et al. 2016b) were found after OT administration in recently exposed trauma victims, in line with OT effects found in healthy females (Domes et al. 2010; Lischke et al. 2012). Individuals with recent trauma exposure also showed OT-related reduced functional connectivity between the PFC and amygdala, reflecting decreased top-down control over the hyperactive amygdala and increased re-experiencing intensity (Frijling et al. 2016a, b). Repeated OT administration for 8 consecutive days starting maximum 12 days after trauma exposure also showed no difference in PTSD symptom severity at 1.5 months after trauma exposure compared with placebo (van Zuiden et al. 2017). However, trauma-exposed individuals with a high level of initial acute distress reported lower PTSD symptoms at follow-up after having received OT repeatedly compared with individuals with initial high distress in placebo condition (van Zuiden et al. 2017), indicating potential of intranasal OT exclusively for those with high acute distress levels after trauma.

\section{Endogenous and exogenous OT in the peripartum period}

Throughout pregnancy, the majority of women show a slight increase of endogenous OT levels and a subsequent decline at 2 months postpartum (Feldman et al. 2007; Levine et al. 2007; Prevost et al., 2014; van der Post et al. 1997). During the early postpartum (lactation) period, endogenous OT levels are generally elevated due to increased cerebral OT in order to buffer stress reactivity (e.g., Bell et al. 2014; Cox et al. 2015; Grewen et al. 2010) with reduced perception of negative environmental stimuli (Altemus et al. 2001; Heinrichs et al. 2001). Intravenous OT administration for augmentation of labor is a frequently performed obstetric intervention (i.e., 25\%) in most Western countries (Boie et al. 2018). However, it has been postulated that this might interfere with normal neurobiological adaptations around birth, thereby potentially affecting maternal and infant mental health. Despite some positive associations of intrapartum synthetic OT with higher plasma OT levels postpartum (Gu et al. 2016), lower aggression (Prevost et al. 2014), and higher socialization during breastfeeding (Jonas et al. 2009), other studies point to adverse outcomes associated with high doses of intrapartum synthetic OT such as less successful breastfeeding (Olza Fernández et al. 2012; Gu et al. 2016) and negative emotional wellbeing of the mother postpartum (i.e., depression and anxiety but not PTSD-symptoms) ( $\mathrm{Gu}$ et al. 2016). Findings from a large retrospective population-based study also suggest that women exposed to intrapartum synthetic OT have a greater risk of developing depressive and/or anxiety disorders within the first year postpartum as compared with women not exposed to intrapartum synthetic OT, irrespective of pre-pregnancy depression or anxiety or mode of delivery (Kroll-Desrosiers et al. 2017). These potential adverse effects of synthetic intrapartum OT could be explained by desensitization of the OTR due to excessive amounts of synthetic OT. More specifically, due to OT agonist stimulation, a (temporarily) decrease in binding sites takes place (Conti et al. 2008) and, based studies in rats and mice, Gimpl and Fahrenholz suggest that internalization of the human OTR may make OTRs unavailable for further OT binding (Gimpl and Fahrenholz 2001; Wahl 2004). However, the current state of scientific evidence does not allow us to make causal inferences regarding the association between the retrospectively assessed relationship of intrapartum synthetic OT with adverse wellbeing from nationwide collected health data.

In Table 2, results from OT administration trials in postpartum women are presented. After OT administration, an increase of reward-related mesolimbic functional activation in ventral tegmental area (but not nucleus accumbens) to images of crying infants in both postpartum and nulliparous women was found (compared with placebo) (Gregory et al. 2015). Findings are in line with preclinical studies showing increased maternal caretaking behavior after OT injections in the ventral tegmental area of rats (Pedersen et al. 1994), which suggests improved motivation for caretaking behavior under OT in healthy postpartum women. This is of importance for women with avoidant attachment styles who are at increased risk for developing PTSD-FC after operative deliveries (Ayers et al. 2014). However, activation of the amygdala (part of the salience network) was reduced in response to negative images after OT administration in nulliparous women, while a blunted amygdala reaction and reduced arousal to all types of infant images was found in postpartum women only in the placebo condition (Rupp et al. 2013, 2014). Again, saturation of available OTRs caused by already higher endogenous OT levels around birth could explain this blunted reaction to OT in postpartum women (Rupp et al. 2014).

In depressed postpartum women, intranasal OT (compared with placebo) in advance of infant interaction sessions, negatively affected self-reported maternal mood and child behavior although quality of mother-infant interaction improved (Mah et al. 2013). OT administration in postpartum depressed women also increased the salience of infant crying and maternal protectiveness (Mah et al. 2015, 2017). Maternal protectiveness is however an adaptive maternal postpartum reaction not linked to mood (Mayes and Leckman 2007). Nonetheless, OT also enhanced the potential of mothers to choose harsh caregiving strategies in response to crying infants (Mah et al. 


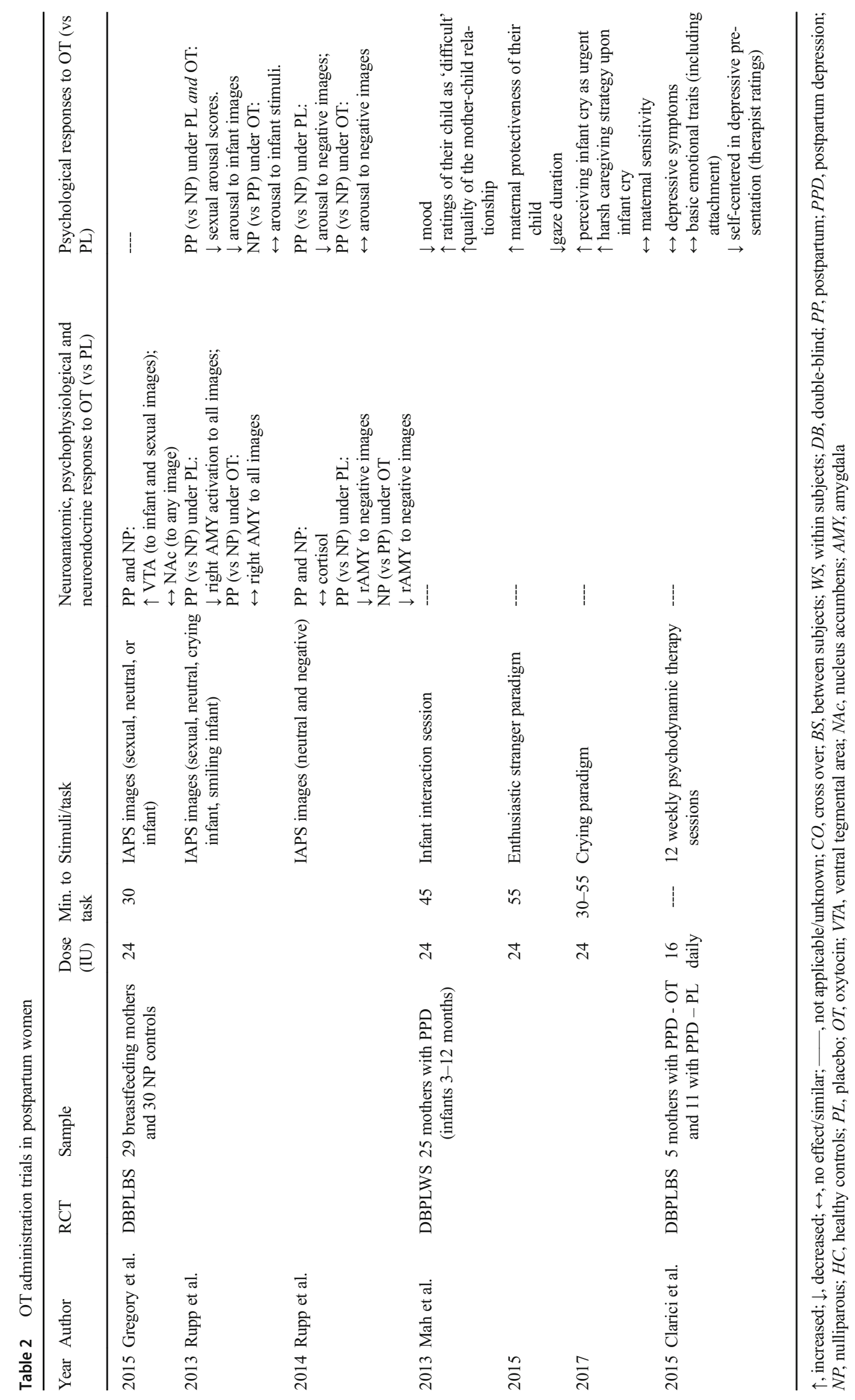


2017). This is of importance, since mothers with depression already have an increased likelihood to be less emotionally responsive and to respond with more aggressiveness to their children and exogenous OT may thus increase this behavior (Drury et al. 2016). In healthy women, intranasal OT is associated with increased salience of threat-related stimuli (Domes et al. 2010) and aggressiveness, particularly to out-group members while OT tends to increase trustfulness to in-group members (De Dreu et al. 2010). In distressed women, OT may exert different effects than in healthy women, for example, poorer couple conflict behaviors were found in distressed substance abusing women after OT (Flanagan et al. 2018a). This, in sum, suggests that the potential effects of OT depend on women's mood and circumstances (Bartz et al. 2011; Olff et al. 2013). Recent findings suggest that OT may not operate as expected in individuals with high levels of early (child) adversity and that the individuals' social context should be carefully considered in the administration of OT (Graustella and Macleod 2012). Furthermore, intranasal OT was more beneficial on mid- and long-term (1.5 to 6 months) PTSD symptom course after acute trauma exposure in women with hormonal contraception use (resembling high levels of estrogens and low levels of progesterone) (Engel et al. 2019). The latter finding is in line with previous links suggested between hormonal status and PTSD risk in women (Garcia et al. 2018).

No additional effects of daily OT during the treatment period of 12 weeks on depression or on attachment-like emotional traits in postpartum depressed mothers were found in a small trial of Clarici et al. (2015). Only self-centeredness during treatment was significantly lower in the OT group compared with placebo (Clarici et al. 2015). This may reflect an OT-related increase of the motivation to socially interact which could be meaningful for the formation of a positive therapeutic alliance. Indeed, a positive social bond (such as trusted therapist) may be necessary for OT to exert its modulating effect (i.e., decrease of fear (and amygdala) in PTSD (Charuvastra and Cloitre 2008). As described earlier, OT administration in PTSD patients has shown to improve the motivation to engage in activities and compassion and to reduce nervousness and anxiety both reflected in an increase of reward-related functional activation and reduced activity and connectivity in the salience network (Koch et al. 2016a, b).

\section{Clinical implications and suggestions for future research}

At the time of drafting this review, no trials of intranasal OT administered in postpartum (traumatized) women with (symptoms of) PTSD-FC were available. This indicates a critical unexplored area of research. The overview of literature presented in this review, however, provides some specific directives and refinements for future research in women with PTSD-FC and/ or acutely traumatized women after childbirth. Research is needed to examine whether and how OT administration might effectively reduce or prevent PTSD-FC particularly in women at high-risk for PTSD-FC. Future studies should take into account that the effects of OT may be modulated by timing and dosage of OT administration. PTSD models in rodents have shown timing effects of OT administration in terms of traumatic memory consolidation and fear extinction (Toth et al. 2012; Eskandarian et al. 2013) and anxiolytic effects produced by repeated OT administration (Janezic et al. 2016).

Furthermore, findings reviewed in this article are predominantly based on immediate effects of short-term OT administration but the few studies available on effects of repeated intranasal OT administration point towards clinically meaningful symptom improvements in PTSD (Flanagan et al. 2018b) and acutely distressed individuals after trauma exposure (van Zuiden et al. 2017). Therefore, adequately powered trials are warranted to examine whether repeated low-dose intranasal OT administration is an early preventive intervention for PTSD-FC in women with a high level of acute childbirth-related distress. Future trials are also needed to evaluate whether repeated intranasal OT administration as a therapeutic adjunct has the ability to increase tolerability of prolonged exposure, enhance therapeutic alliance, and help with memory consolidation and fear extinction in PTSD in general and/or following childbirth (Clarici et al. 2015; Nawijn et al. 2016; Sack et al. 2017; Flanagan et al. 2018b). Furthermore, differential effects of postpartum intranasal OT in women already exposed to various amounts of intrapartum synthetic OT should be explored in future research.

The findings reviewed here also suggest differential effects of intranasal OT according to specific individual characteristics or circumstances of postpartum women (Bartz et al. 2011). For example, the effect of intranasal OT in women with PTSD-FC might be modified by comorbid depression (Kim et al. 2014), lactation (i.e., breastfeeding or formula-feeding) (Cox et al. 2015), history of early adversities (Pierrehumbert et al. 2010; Fan et al. 2015), or lack of social support or relationship distress (Taylor et al. 2006). In PTSD-FC, this picture is further complicated by normal neuroendocrine and functional neuroanatomic alterations around parturition (e.g., reduced stress responsiveness in the HPA axis and blunted reaction to intranasal OT). Therefore, future research should also examine the endogenous OT system in the development and maintenance of PTSD-FC.

Conclusions Collectively, the evidence from non-obstetric traumatized samples with or without PTSD and from peripartum healthy or depressed samples implies an important role for the oxytocinergic system in the neuroendocrine dysregulations in women with (or at high risk for) PTSDFC. The restorative functional neuroanatomic and psychological effects of OT further strengthen the motivation to examine the ability of OT to augment psychotherapeutic interventions in PTSD-FC with or without comorbid depression. Despite 
availability of reviews on intranasal oxytocin in postpartum depression (Kim et al. 2014; Moura et al. 2016) and parenting behavior (van IJzendoorn and Bakermans-Kranenburg 2016; Szymanska et al. 2017), fundamental observational research is necessary to delineate the nuances of the oxytocinergic system in PTSD-FC. Moreover, the potentially adverse effects of intranasal OT on mood and the increased fear processing and reduced top-down control over amygdala activation in women with acute trauma exposure warrant cautionary use of intranasal OT in postpartum women. For acutely traumatized postpartum women, preventive interventions that aim at social (i.e., partner) and obstetric staff support in order to further promote endogenous oxytocin release may be more beneficial in preventing PTSD-FC (van Heumen et al. 2018; van Steijn et al. 2019). Finally, because individual and situational circumstances matter, future clinical research trials that provide possibilities to examine the more individualized therapeutic response of exogenous OT, for example by using personalized methods, might give directions on who will obtain most benefit from exogenous OT.

\section{Compliance with ethical standards}

Research involving human participants and/or animals Not applicable.

Conflict of interest The authors declare that they have no conflicts of interest.

Informed consent Not applicable.

Open Access This article is distributed under the terms of the Creative Commons Attribution 4.0 International License (http:// creativecommons.org/licenses/by/4.0/), which permits unrestricted use, distribution, and reproduction in any medium, provided you give appropriate credit to the original author(s) and the source, provide a link to the Creative Commons license, and indicate if changes were made.

\section{References}

Acevedo-Rodriguez A, Mani SK, Handa RJ (2015) Oxytocin and estrogen receptor $\beta$ in the brain: an overview. Front Endocrinol (Lausanne) 6:160. https://doi.org/10.3389/fendo.2015.00160

Altemus M, Redwine LS, Leong YM, Frye CA, Porges SW, Sue Carter C (2001) Responses to laboratory psychosocial stress in postpartum women. Psychosom Med 63:814-821

American Psychiatric Association (2013) Diagnostic and statistical manual of mental disorders, 5th edn. American Psychiatric Publishing, Inc

Ayers S, McKenzie-McHarg K, Eagle A (2007) Cognitive behaviour therapy for postnatal post-traumatic stress disorder: case studies. J Psychosom Obstet Gynaecol 28:177-184. https://doi.org/10.1080/ 01674820601142957

Ayers S, Harris R, Sawyer A et al (2009) Posttraumatic stress disorder after childbirth: analysis of symptom presentation and sampling. $\mathrm{J}$ Affect Disord 119:200-204. https://doi.org/10.1016/j.jad.2009.02. 029
Ayers S, Jessop D, Pike A, Parfitt Y, Ford E (2014) The role of adult attachment style, birth intervention and support in posttraumatic stress after childbirth: a prospective study. J Affect Disord 155: 295-298. https://doi.org/10.1016/j.jad.2013.10.022

Ayers S, Bond R, Bertullies S, Wijma K (2016) The aetiology of posttraumatic stress following childbirth: a meta-analysis and theoretical framework. Psychol Med 46:1121-1134

Baas MAM, Stramrood CAI, Dijksman LM, de Jongh A, van Pampus MG (2017) The OptiMUM-study: EMDR therapy in pregnant women with posttraumatic stress disorder after previous childbirth and pregnant women with fear of childbirth: design of a multicentre randomized controlled trial. Eur J Psychotraumatol 8:1293315. https://doi.org/10.1080/20008198.2017.1293315

Bakermans-Kranenburg MJ, van IJzendoorn MH (2013) Sniffing around oxytocin: review and meta-analyses of trials in healthy and clinical groups with implications for pharmacotherapy. Transl Psychiatry 3: e258-e258. https://doi.org/10.1038/tp.2013.34

Ballard CG, Stanley AK, Brockington IF (1995) Post-traumatic stress disorder (PTSD) after childbirth. Br J Psychiatry 166:525-528

Bartz JA, Zaki J, Bolger N, Ochsner KN (2011) Social effects of oxytocin in humans: context and person matter. Trends Cogn Sci 15:301-309. https://doi.org/10.1016/j.tics.2011.05.002

Bell AF, Erickson EN, Carter CS (2014) Beyond labor: the role of natural and synthetic oxytocin in the transition to motherhood. J Midwifery Womens Health 59:35-42: quiz 108. https://doi.org/10.1111/jmwh. 12101

Birur B, Moore NC, Davis LL (2017) An evidence-based review of early intervention and prevention of posttraumatic stress disorder. Community Ment Health J 53:183-201. https://doi.org/10.1007/ s10597-016-0047-x

Boie S, Glavind J, Velu AV, Mol BWJ, Uldbjerg N, de Graaf I, Thornton JG, Bor P, Bakker JJH, Cochrane Pregnancy and Childbirth Group (2018) Discontinuation of intravenous oxytocin in the active phase of induced labour. Cochrane Database Syst Rev. https://doi.org/10. 1002/14651858.CD012274.pub2

Boorman RJ, Devilly GJ, Gamble J, et al (2014) Childbirth and criteria for traumatic events. https://doi.org/10.1016/j.midw.2013.03.001

Bradley R, Greene J, Russ E, Dutra L, Westen D (2005) A multidimensional meta-analysis of psychotherapy for PTSD. Am J Psychiatry 162:214-227. https://doi.org/10.1176/appi.ajp.162.2.214

Brunton PJ, Bales J, Russell JA (2012) Allopregnanolone and induction of endogenous opioid inhibition of oxytocin responses to immune stress in pregnant rats. J Neuroendocrinol 24:690-700. https://doi. org/10.1111/j.1365-2826.2012.02295.x

Cao C, Wang L, Wang R, Qing Y, Zhang J (2014) Oxytocin is associated with PTSD's anxious arousal symptoms in Chinese male earthquake survivors. Eur J Psychotraumatol 5:26530

Charuvastra A, Cloitre M (2008) Social bonds and posttraumatic stress disorder. Annu Rev Psychol 59:301-328. https://doi.org/10.1146/ annurev.psych.58.110405.085650

Clarici A, Pellizzoni S, Guaschino S, Alberico S, Bembich S, Giuliani R, Short A, Guarino G, Panksepp J (2015) Intranasal adminsitration of oxytocin in postnatal depression: implications for psychodynamic psychotherapy from a randomized double-blind pilot study. Front Psychol 6. https://doi.org/10.3389/fpsyg.2015.00426

Cloitre M (2009) Effective psychotherapies for posttraumatic stress disorder: a review and critique. CNS Spectr 14:32-43

Conti F, Sertic S, Reversi A, Chini B (2008) Intracellular trafficking of the human oxytocin receptor: evidence of receptor recycling via a Rab4/ Rab5 "short cycle". AJP Endocrinol Metab 296:E532-E542. https:// doi.org/10.1152/ajpendo.90590.2008

Cook N, Ayers S, Horsch A (2018) Maternal posttraumatic stress disorder during the perinatal period and child outcomes: a systematic review. J Affect Disord 225:18-31. https://doi.org/10.1016/j.jad.2017.07. 045 
Cox EQ, Stuebe A, Pearson B, Grewen K, Rubinow D, Meltzer-Brody S (2015) Oxytocin and HPA stress axis reactivity in postpartum women. Psychoneuroendocrinology 55:164-172. https://doi.org/10. 1016/j.psyneuen.2015.02.009

Dabrowska J, Hazra R, Ahern TH, Guo JD, McDonald AJ, Mascagni F, Muller JF, Young LJ, Rainnie DG (2011) Neuroanatomical evidence for reciprocal regulation of the corticotrophin-releasing factor and oxytocin systems in the hypothalamus and the bed nucleus of the stria terminalis of the rat: implications for balancing stress and affect. Psychoneuroendocrinology 36:1312-1326. https://doi.org/10.1016/ j.psyneuen.2011.03.003

De Dreu CKW, Greer LL, Handgraaf MJJ et al (2010) The neuropeptide oxytocin regulates parochial altruism in intergroup conflict among humans. Science 328:1408-1411. https://doi.org/10.1126/science. 1189047

de Graaff LF, Honig A, van Pampus MG, Stramrood CAI (2018) Preventing post-traumatic stress disorder following childbirth and traumatic birth experiences: a systematic review. Acta Obstet Gynecol Scand

Ditzen B, Nater UM, Schaer M, la Marca R, Bodenmann G, Ehlert U, Heinrichs M (2013) Sex-specific effects of intranasal oxytocin on autonomic nervous system and emotional responses to couple conflict. Soc Cogn Affect Neurosci 8:897-902. https://doi.org/10.1093/ scan $/ \mathrm{nss} 083$

Domes G, Heinrichs M, Gläscher J, Büchel C, Braus DF, Herpertz SC (2007) Oxytocin attenuates amygdala responses to emotional faces regardless of valence. Biol Psychiatry 62:1187-1190. https://doi. org/10.1016/j.biopsych.2007.03.025

Domes G, Lischke A, Berger C, Grossmann A, Hauenstein K, Heinrichs M, Herpertz SC (2010) Effects of intranasal oxytocin on emotional face processing in women. Psychoneuroendocrinology 35:83-93. https://doi.org/10.1016/j.psyneuen.2009.06.016

Drury SS, Scaramella L, Zeanah CH (2016) The neurobiological impact of postpartum maternal depression: prevention and intervention approaches. Child Adolesc Psychiatr Clin N Am 25:179-200

Dunlop BW, Mansson E, Gerardi M (2012) Pharmacological innovations for posttraumatic stress disorder and medication- enhanced psychotherapy. Curr Pharm Des 18:5645-5658

Engel S, van Zuiden M, Frijling JL et al (2019) Patterns of recovery from early posttraumatic stress symptoms after a preventive intervention with Oxytocin: Hormonal Contraception Use Is a Prognostic Factor. Biol Psychiatry. https://doi.org/10.1016/J.BIOPSYCH.2019.01.014

Eskandarian S, Vafaei AA, Vaezi GH, Taherian F, Kashefi A, RashidyPour A (2013) Effects of systemic administration of oxytocin on contextual fear extinction in a rat model of post-traumatic stress disorder. Basic Clin Neurosci 4:315-322

Fan Y, Pestke K, Feeser M, Aust S, Pruessner JC, Böker H, Bajbouj M, Grimm S (2015) Amygdala-hippocampal connectivity changes during acute psychosocial stress: joint effect of early life stress and oxytocin. Neuropsychopharmacology 40:2736-2744. https://doi. org/10.1038/npp.2015.123

Feldman R, Weller A, Zagoory-Sharon O, Levine A (2007) Evidence for a neuroendocrinological foundation of human affiliation: plasma oxytocin levels across pregnancy and the postpartum period predict mother-infant bonding. Psychol Sci 18:965-970. https://doi.org/10. 1111/j.1467-9280.2007.02010.x

Feng C, Hackett PD, DeMarco AC et al (2015) Oxytocin and vasopressin effects on the neural response to social cooperation are modulated by sex in humans. Brain Imaging Behav 9:754-764. https://doi.org/10. 1007/s11682-014-9333-9

Flanagan JC, Fischer MS, Nietert PJ, Back SE, Maria MMS, Snead A, Brady KT (2018a) Effects of oxytocin on cortisol reactivity and conflict resolution behaviors among couples with substance misuse. Psychiatry Res 260:346-352. https://doi.org/10.1016/j.psychres. 2017.12.003
Flanagan JC, Sippel LM, Wahlquist A, Moran-Santa Maria MM, Back SE (2018b) Augmenting prolonged exposure therapy for PTSD with intranasal oxytocin: a randomized, placebo-controlled pilot trial. J Psychiatr Res 98:64-69. https://doi.org/10.1016/j.jpsychires.2017. 12.014

Flanagan JC, Hand A, Jarnecke A, Moran-Santa Maria MM, Brady KT, Joseph JE (2018c) Effects of oxytocin on working memory and executive control system connectivity in PTSD. Exp Clin Psychopharmacol 26:391-402. https://doi.org/10.1037/pha0000197

Frijling JL, van Zuiden M, Nawijn L, Koch SBJ, Neumann ID, Veltman DJ, Olff M (2015) Salivary oxytocin and vasopressin levels in police officers with and without post-traumatic stress disorder. J Neuroendocrinol 27:743-751. https://doi.org/10.1111/jne.12300

Frijling JL, van Zuiden M, Koch SBJ, Nawijn L, Veltman DJ, Olff M (2016a) Intranasal oxytocin affects amygdala functional connectivity after trauma script-driven imagery in distressed recently traumaexposed individuals. Neuropsychopharmacology 41:1286-1296. https://doi.org/10.1038/npp.2015.278

Frijling JL, van Zuiden M, Koch SBJ, Nawijn L, Veltman DJ, Olff M (2016b) Effects of intranasal oxytocin on amygdala reactivity to emotional faces in recently trauma-exposed individuals. Soc Cogn Affect Neurosci 11:327-336. https://doi.org/10.1093/scan/nsv116

Garcia MA, Delahanty DL (2017) Oxytocin and other pharmacologic preventive interventions for posttraumatic stress disorder: not a one-size-fits-all approach. Biol Psychiatry 81:977-978

Garcia NM, Walker RS, Zoellner LA (2018) Estrogen, progesterone, and the menstrual cycle: a systematic review of fear learning, intrusive memories, and PTSD. Clin Psychol Rev 66:80-96. https://doi.org/ 10.1016/J.CPR.2018.06.005

Gatta E, Mairesse J, Deruyter L, Marrocco J, van Camp G, Bouwalerh H, Lo Guidice JM, Morley-Fletcher S, Nicoletti F, Maccari S (2018) Reduced maternal behavior caused by gestational stress is predictive of life span changes in risk-taking behavior and gene expression due to altering of the stress/anti-stress balance. Neurotoxicology 66: 138-149. https://doi.org/10.1016/j.neuro.2018.04.005

Gimpl G, Fahrenholz F (2001) The oxytocin receptor system: structure, function, and regulation. Physiol Rev 81:629-683

Graustella AJ, Macleod C (2012) A critical review of the influence of oxytocin nasal spray on social cognition in humans: evidence and future directions. Horm Behav 61:410-418. https://doi.org/10.1016/ j.yhbeh.2012.01.002

Gregory R, Cheng H, Rupp HA, Sengelaub DR, Heiman JR (2015) Oxytocin increases VTA activation to infant and sexual stimuli in nulliparous and postpartum women. Horm Behav 69:82-88. https:// doi.org/10.1016/j.yhbeh.2014.12.009

Grekin R, O'Hara MW (2014) Prevalence and risk factors of postpartum posttraumatic stress disorder: a meta-analysis. Clin.Psychol.Rev. 34: 389-401

Grewen KM, Davenport RE, Light KC (2010) An investigation of plasma and salivary oxytocin responses in breast- and formula-feeding mothers of infants. Psychophysiology 47:625-632. https://doi.org/ 10.1111/j.1469-8986.2009.00968.x

Groppe SE, Gossen A, Rademacher L, Hahn A, Westphal L, Gründer G, Spreckelmeyer KN (2013) Oxytocin influences processing of socially relevant cues in the ventral tegmental area of the human brain. Biol Psychiatry 74:172-179. https://doi.org/10.1016/j.biopsych. 2012.12.023

Gu V, Feeley N, Gold I, Hayton B, Robins S, Mackinnon A, Samuel S, Carter CS, Zelkowitz P (2016) Intrapartum synthetic oxytocin and its effects on maternal well-being at 2 months postpartum. Birth 43: 28-35. https://doi.org/10.1111/birt.12198

Heinrichs M, Meinlschmidt G, Neumann I, Wagner S, Kirschbaum C, Ehlert U, Hellhammer DH (2001) Effects of suckling on hypothalamic-pituitary-adrenal axis responses to psychosocial stress in postpartum lactating women. J Clin Endocrinol Metab 86:47984804. https://doi.org/10.1210/jcem.86.10.7919 
Hillerer KM, Reber SO, Neumann ID, Slattery DA (2011) Exposure to chronic pregnancy stress reverses peripartum-associated adaptations: implications for postpartum anxiety and mood disorders. Endocrinology 152:3930-3940

Hillerer KM, Jacobs VR, Fischer T, Aigner L (2014) The maternal brain: an organ with peripartal plasticity. Neural Plast 2014:574159 574120. https://doi.org/10.1155/2014/574159

Horsch A, Vial Y, Eline Favrod C, et al (2017) Reducing intrusive traumatic memories after emergency caesarean section: a proof-ofprinciple randomized controlled study. https://doi.org/10.1016/j. brat.2017.03.018

Janezic EM, Uppalapati S, Nagl S, Contreras M, French ED, Fellous JM (2016) Beneficial effects of chronic oxytocin administration and social co-housing in a rodent model of post-traumatic stress disorder. Behav Pharmacol 27:704-717. https://doi.org/10.1097/FBP. 0000000000000270

Jonas K, Johansson LM, Nissen E et al (2009) Effects of intrapartum oxytocin administration and epidural analgesia on the concentration of plasma oxytocin and prolactin, in response to suckling during the second day postpartum. Breastfeed Med 4:71-82. https://doi.org/10. 1089/bfm.2008.0002

Julian MM, Rosenblum KL, Doom JR, Leung CYY, Lumeng JC, Cruz MG, Vazquez DM, Miller AL (2018) Oxytocin and parenting behavior among impoverished mothers with low vs. high early life stress. Arch Womens Ment Health 21:375-382. https://doi.org/10. 1007/s00737-017-0798-6

Kim S, Strathearn L (2016) Oxytocin and maternal brain plasticity. New Dir Child Adolesc Dev 2016:59-72. https://doi.org/10.1002/cad. 20170

Kim S, Soeken TA, Cromer SJ, Martinez SR, Hardy LR, Strathearn L (2014) Oxytocin and postpartum depression: delivering on what's known and what's not. Brain Res 1580:219-232. https://doi.org/10. 1016/j.brainres.2013.11.009

Kirsch P, Esslinger C, Chen Q, Mier D, Lis S, Siddhanti S, Gruppe H, Mattay VS, Gallhofer B, Meyer-Lindenberg A (2005) Oxytocin modulates neural circuitry for social cognition and fear in humans. J Neurosci 25:11489-11493. https://doi.org/10.1523/JNEUROSCI. 3984-05.2005

Koch SB, van Zuiden M, Nawijn L et al (2014) Intranasal oxytocin as strategy for medication-enhanced psychotherapy of PTSD: salience processing and fear inhibition processes. Psychoneuroendocrinology 40: 242-256. https://doi.org/10.1016/j.psyneuen.2013.11.018

Koch SB, van Zuiden M, Nawijn L et al (2016a) Intranasal oxytocin administration dampens amygdala reactivity towards emotional faces in male and female PTSD patients. Neuropsychopharmacology 41:1495-1504. https://doi.org/10.1038/npp.2015.299

Koch SB, van Zuiden M, Nawijn L et al (2016b) Intranasal oxytocin normalizes amygdala functional connectivity in posttraumatic stress disorder. Neuropsychopharmacology 41:2041-2051. https://doi. org/10.1038/npp.2016.1

Koen N, Brittain K, Donald KA, Barnett W, Koopowitz S, Maré K, Zar HJ, Stein DJ (2016) Psychological trauma and posttraumatic stress disorder: risk factors and associations with birth outcomes in the Drakenstein Child Health Study. Eur J Psychotraumatol 7:28720. https://doi.org/10.3402/ejpt.v7.28720

König J, Schmid S, Löser E, Neumann O, Buchholz S, Kästner R (2016) Interplay of demographic variables, birth experience, and initial reactions in the prediction of symptoms of posttraumatic stress one year after giving birth. Eur J Psychotraumatol 7:32377. https://doi. org/10.3402/ejpt.v7.32377

Kroll-Desrosiers AR, Nephew BC, Babb JA, Guilarte-Walker Y, Moore Simas TA, Deligiannidis KM (2017) Association of peripartum synthetic oxytocin administration and depressive and anxiety disorders within the first postpartum year. Depress Anxiety 34:137-146. https://doi.org/10.1002/da.22599
Levine A, Zagoory-Sharon O, Feldman R, Weller A (2007) Oxytocin during pregnancy and early postpartum: individual patterns and maternal-fetal attachment. Peptides 28:1162-1169. https://doi.org/ 10.1016/j.peptides.2007.04.016

Liberzon I, Sripada CS (2008) The functional neuroanatomy of PTSD: a critical review. Prog Brain Res 167:151-169. https://doi.org/10. 1016/S0079-6123(07)67011-3

Lischke A, Gamer M, Berger C, Grossmann A, Hauenstein K, Heinrichs M, Herpertz SC, Domes G (2012) Oxytocin increases amygdala reactivity to threatening scenes in females. Psychoneuroendocrinology 37:14311438. https://doi.org/10.1016/j.psyneuen.2012.01.011

Love TM (2014) Oxytocin, motivation and the role of dopamine. Pharmacol Biochem Behav 119:49-60. https://doi.org/10.1016/j. pbb.2013.06.011

Maccari S, Krugers HJ, Morley-Fletcher S, Szyf M, Brunton PJ (2014) The consequences of early-life adversity: neurobiological, behavioural and epigenetic adaptations. J Neuroendocrinol 26:707-723. https://doi.org/10.1111/jne.12175

MacDonald K, Feifel D (2014) Oxytocin's role in anxiety: a critical appraisal. Brain Res 1580:22-56. https://doi.org/10.1016/j.brainres. 2014.01.025

Mah BL, Van Ijzendoorn MH, Smith R, Bakermans-Kranenburg MJ (2013) Oxytocin in postnatally depressed mothers: its influence on mood and expressed emotion. Prog Neuro-Psychopharmacol Biol Psychiatry 40:267-272. https://doi.org/10.1016/j.pnpbp.2012.10. 005

Mah BL, Bakermans-Kranenburg MJ, Van IJzendoorn MH, Smith R (2015) Oxytocin promotes protective behavior in depressed mothers: a pilot study with the enthusiastic stranger paradigm. Depress Anxiety 32:76-81. https://doi.org/10.1002/da.22245

Mah BL, Van Ijzendoorn MH, Out D et al (2017) The effects of intranasal oxytocin administration on sensitive caregiving in mothers with postnatal depression. Child Psychiatry Hum Dev 48:308-315. https://doi.org/10.1007/s10578-016-0642-7

Mayes LC, Leckman JF (2007) Parental representations and subclinical changes in postpartum mood. Infant Ment Health J 28:281-295. https://doi.org/10.1002/imhj.20136

McDonald S, Slade P, Spiby H, Iles J (2011) Post-traumatic stress symptoms, parenting stress and mother-child relationships following childbirth and at 2 years postpartum. J Psychosom Obstet Gynaecol 32:141-146. https://doi.org/10.3109/0167482X.2011. 596962

McKenzie-McHarg K, Ayers S, Ford E, Horsch A, Jomeen J, Sawyer A, Stramrood C, Thomson G, Slade P (2015) Post-traumatic stress disorder following childbirth: an update of current issues and recommendations for future research. J Reprod Infant Psychol 33:219 237. https://doi.org/10.1080/02646838.2015.1031646

Meyer-Lindenberg A, Domes G, Kirsch P, Heinrichs M (2011) Oxytocin and vasopressin in the human brain: social neuropeptides for translational medicine. Nat Rev Neurosci 12:524-538. https://doi.org/10. 1038/nrn3044

Moura D, Canavarro MC, Figueiredo-Braga M (2016) Oxytocin and depression in the perinatal period-a systematic review. Arch Womens Ment Health 19:561-570. https://doi.org/10.1007/ s00737-016-0643-3

National Institute for Clinical Excellence (2014) Antenatal and postnatal mental health: clinical management and service guidance

Nawijn L, van Zuiden M, Koch SBJ, Frijling JL, Veltman DJ, Olff M (2016) Intranasal oxytocin enhances neural processing of monetary reward and loss in post-traumatic stress disorder and traumatized controls. Psychoneuroendocrinology 66:228-237. https://doi.org/ 10.1016/j.psyneuen.2016.01.020

Nawijn L, van Zuiden M, Koch SBJ, Frijling JL, Veltman DJ, Olff M (2017) Intranasal oxytocin increases neural responses to social reward in post-traumatic stress disorder. Soc Cogn Affect Neurosci 12: 212-223. https://doi.org/10.1093/scan/nsw123 
Nieminen K, Berg I, Frankenstein K, et al (2017) Cognitive behaviour therapy internet-provided cognitive behaviour therapy of posttraumatic stress symptoms following childbirth - a randomized controlled trial. https://doi.org/10.1080/16506073.2016.1169626

Nishi D, Hashimoto K, Noguchi H, Kim Y, Matsuoka Y (2015) Serum oxytocin, posttraumatic coping and C-reactive protein in motor vehicle accident survivors by gender. Neuropsychobiology 71:196201

Olazábal DE (2018) Role of oxytocin in parental behaviour. J Neuroendocrinol 30:e12594. https://doi.org/10.1111/jne.12594

Olff M, Frijling JL, Kubzansky LD, Bradley B, Ellenbogen MA, Cardoso C, Bartz JA, Yee JR, van Zuiden M (2013) The role of oxytocin in social bonding, stress regulation and mental health: an update on the moderating effects of context and interindividual differences. Psychoneuroendocrinology 38:1883-1894. https://doi.org/10.1016/ j.psyneuen.2013.06.019

Olza Fernández I, Marín Gabriel M, Malalana Martínez A, FernándezCañadas Morillo A, López Sánchez F, Costarelli V (2012) Newborn feeding behaviour depressed by intrapartum oxytocin: a pilot study. Acta Paediatr 101:749-754. https://doi.org/10.1111/j.1651-2227. 2012.02668.x

Palgi S, Klein E, Shamay-Tsoory SG (2016) Oxytocin improves compassion toward women among patients with PTSD. Psychoneuroendocrinology 64:143-149. https://doi.org/10.1016/j. psyneuen.2015.11.008

Palgi S, Klein E, Shamay-Tsoory S (2017) The role of oxytocin in empathy in PTSD. Psychol Trauma 9:70-75. https://doi.org/10.1037/ tra0000142

Parfitt Y, Ayers S (2014) Transition to parenthood and mental health in first-time parents. Infant Ment Health J 35:263-273

Pedersen CA, Caldwell JD, Walker C, Ayers G, Mason GA (1994) Oxytocin activates the postpartum onset of rat maternal behavior in the ventral tegmental and medial preoptic areas. Behav Neurosci 108:1163-1171

Pierrehumbert B, Torrisi R, Laufer D, Halfon O, Ansermet F, Beck Popovic M (2010) Oxytocin response to an experimental psychosocial challenge in adults exposed to traumatic experiences during childhood or adolescence. Neuroscience 166:168-177. https://doi. org/10.1016/j.neuroscience.2009.12.016

Post C, Leuner B (2018) The maternal reward system in postpartum depression. Arch Womens Ment Health 22:1-13. https://doi.org/ 10.1007/s00737-018-0926-y

Prevost M, Zelkowitz P, Tulandi T et al (2014) Oxytocin in pregnancy and the postpartum: relations to labor and its management. Front Public Health 2:1

Protopopescu X, Pan H, Tuescher O, Cloitre M, Goldstein M, Engelien W, Epstein J, Yang Y, Gorman J, LeDoux J, Silbersweig D, Stern E (2005) Differential time courses and specificity of amygdala activity in posttraumatic stress disorder subjects and normal control subjects. Biol Psychiatry 57:464-473. https://doi.org/10.1016/j.biopsych. 2004.12.026

Quidé Y, Witteveen AB, El-Hage W, Veltman DJ, Olff M (2012) Differences between effects of psychological versus pharmacological treatments on functional and morphological brain alterations in anxiety disorders and major depressive disorder: a systematic review. Neurosci Biobehav Rev 36:626-44. https://doi.org/10.1016/j. neubiorev.2011.09.004

Riem MME, van IJzendoorn MH, Tops M et al (2012) No laughing matter: intranasal oxytocin administration changes functional brain connectivity during exposure to infant laughter. Neuropsychopharmacology 37:1257-1266. https://doi.org/10. 1038/npp.2011.313

Rilling JK, Demarco AC, Hackett PD et al (2014) Sex differences in the neural and behavioral response to intranasal oxytocin and vasopressin during human social interaction. Psychoneuroendocrinology 39: 237-248
Rupp HA, James TW, Ketterson ED, Sengelaub DR, Ditzen B, Heiman JR (2013) Lower sexual interest in postpartum women: relationship to amygdala activation and intranasal oxytocin. Horm Behav 63: 114-121. https://doi.org/10.1016/j.yhbeh.2012.10.007

Rupp HA, James TW, Ketterson ED, Sengelaub DR, Ditzen B, Heiman JR (2014) Amygdala response to negative images in postpartum vs nulliparous women and intranasal oxytocin. Soc Cogn Affect Neurosci 9:48-54. https://doi.org/10.1093/scan/nss 100

Sabihi S, Dong SM, Durosko NE, Leuner B (2014) Oxytocin in the medial prefrontal cortex regulates maternal care, maternal aggression and anxiety during the postpartum period. Front Behav Neurosci 8:258. https://doi.org/10.3389/fnbeh.2014.00258

Sack M, Spieler D, Wizelman L, Epple G, Stich J, Zaba M, Schmidt U (2017) Intranasal oxytocin reduces provoked symptoms in female patients with posttraumatic stress disorder despite exerting sympathomimetic and positive chronotropic effects in a randomized controlled trial. 15. https://doi.org/10.1186/s12916-017-0801-0

Samuel S, Hayton B, Gold I, Feeley N, Carter CS, Zelkowitz P (2015) Maternal mental health moderates the relationship between oxytocin and interactive behavior. Infant Ment Health J 36:415-426. https:// doi.org/10.1002/imhj.21521

Sandström M, Wiberg B, Wikman M, Willman AK, Högberg U (2008) A pilot study of eye movement desensitisation and reprocessing treatment (EMDR) for post-traumatic stress after childbirth. Midwifery 24:62-73. https://doi.org/10.1016/j.midw.2006.07.008

Schottenbauer MA, Glass CR, Arnkoff DB, Tendick V, Gray SH (2008) Nonresponse and dropout rates in outcome studies on PTSD: review and methodological considerations. Psychiatry 71:134-168. https:// doi.org/10.1521/psyc.2008.71.2.134

Seng J, Miller J, Sperlich M, van de Ven CJM, Brown S, Carter CS, Liberzon I (2013) Exploring dissociation and oxytocin as pathways between trauma exposure and trauma-related hyperemesis gravidarum: a test-of-concept pilot. J Trauma Dissociation 14:40 55. https://doi.org/10.1080/15299732.2012.694594

Sherin JE, Nemeroff CB (2011) Post-traumatic stress disorder: the neurobiological impact of psychological trauma. Dialogues Clin Neurosci 13:263-278

Shin LM, Wright CI, Cannistraro PA, Wedig MM, McMullin K, Martis B, Macklin ML, Lasko NB, Cavanagh SR, Krangel TS, Orr SP, Pitman RK, Whalen PJ, Rauch SL (2005) A functional magnetic resonance imaging study of amygdala and medial prefrontal cortex responses to overtly presented fearful faces in posttraumatic stress disorder. Arch Gen Psychiatry 62:273-281. https://doi.org/10.1001/ archpsyc.62.3.273

Sijbrandij M, Kleiboer A, Bisson JI, Barbui C, Cuijpers P (2015) Pharmacological prevention of post-traumatic stress disorder and acute stress disorder: a systematic review and meta-analysis. Lancet Psychiatry 2:413-421. https://doi.org/10.1016/S22150366(14)00121-7

Skuse DH, Gallagher L (2009) Dopaminergic-neuropeptide interactions in the social brain. Trends Cogn Sci 13:27-35

Smith AS, Wang Z (2012) Salubrious effects of oxytocin on social stressinduced deficits. Horm Behav 61:320-330. https://doi.org/10.1016/ j.yhbeh.2011.11.010

Stramrood C, van der Velde J, Doornbos B et al (2012) The patient observer: eye-movement desensitization and reprocessing for the treatment of posttraumatic stress following childbirth. Birth 39:70 76. https://doi.org/10.1111/j.1523-536X.2011.00517.x

Strathearn L, Fonagy P, Amico J, Montague PR (2009) Adult attachment predicts maternal brain and oxytocin response to infant cues. Neuropsychopharmacology 34:2655-2666. https://doi.org/10. 1038/npp.2009.103

Strathearn L, Iyengar U, Fonagy P, Kim S (2012) Maternal oxytocin response during mother-infant interaction: associations with adult temperament. Horm Behav 61:429-435. https://doi.org/10.1016/j. yhbeh.2012.01.014 
Szymanska M, Schneider M, Chateau-Smith C, Nezelof S, VulliezCoady L (2017) Psychophysiological effects of oxytocin on parent-child interactions: a literature review on oxytocin and parent-child interactions. Psychiatry Clin Neurosci 71:690-705. https://doi.org/10.1111/pcn.12544

Taylor S, Klein L, Lewis BP et al (2000) Biobehavioral responses to stress in females: tend-and-befriend, not fight-or-flight. Psychol Rev 107: $411-429$

Taylor S, Gonzaga GC, Klein LC et al (2006) Relation of oxytocin to psychological stress responses and hypothalamic-pituitaryadrenocortical axis activity in older women. Psychosom Med 68: 238-245. https://doi.org/10.1097/01.psy.0000203242.95990.74

Taylor S, Saphire-Bernstein S, Seeman TE (2010) Are plasma oxytocin in women and plasma vasopressin in men biomarkers of distressed pair-bond relationships? Psychol Sci 21:3-7. https://doi.org/10. 1177/0956797609356507

Toth I, Neumann ID, Slattery DA (2012) Central administration of oxytocin receptor ligands affects cued fear extinction in rats and mice in a timepoint-dependent manner. Psychopharmacology 223:149-158. https://doi.org/10.1007/s00213-012-2702-4

van der Post JA, van Buul BJ, Hart AA et al (1997) Vasopressin and oxytocin levels during normal pregnancy: effects of chronic dietary sodium restriction. J Endocrinol 152:345-354

van Heumen MA, Hollander MH, van Pampus MG, van Dillen J, Stramrood CAI (2018) Psychosocial predictors of postpartum posttraumatic stress disorder in women with a traumatic childbirth experience. Front Psychiatry 9:348. https://doi.org/10.3389/fpsyt. 2018.00348

van IJzendoorn MH, Bakermans-Kranenburg MJ (2016) The role of oxytocin in parenting and as augmentative pharmacotherapy: critical issues and bold conjectures. J Neuroendocrinol 28. https://doi.org/ $10.1111 /$ jne. 12355 van Steijn ME, Scheepstra KWF, Yasar G, Olff M, de Vries MC, van Pampus MG (2019) Occupational well-being in pediatricians-a survey about work-related posttraumatic stress, depression, and anxiety. Eur J Pediatr 178:681-693. https://doi.org/10.1007/s00431019-03334-7

van Zuiden M, Frijling JL, Nawijn L, Koch SBJ, Goslings JC, Luitse JS, Biesheuvel TH, Honig A, Veltman DJ, Olff M (2017) Intranasal oxytocin to prevent posttraumatic stress disorder symptoms: a randomized controlled trial in emergency department patients. Biol Psychiatry 81:1030-1040. https://doi.org/10.1016/j.biopsych.2016. 11.012

Wahl RUR (2004) Could oxytocin administration during labor contribute to autism and related behavioral disorders? - a look at the literature. Med Hypotheses 63:456-460

Yildiz PD, Ayers S, Phillips L (2016) The prevalence of posttraumatic stress disorder in pregnancy and after birth: a systematic review and meta-analysis. J Affect Disord 208:634-645. https://doi.org/10. 1016/j.jad.2016.10.009

Zelkowitz P, Gold I, Feeley N, Hayton B, Carter CS, Tulandi T, Abenhaim HA, Levin P (2014) Psychosocial stress moderates the relationships between oxytocin, perinatal depression, and maternal behavior. Horm Behav 66:351-360. https://doi.org/10.1016/j. yhbeh.2014.06.014

Zoladz PR, Diamond DM (2013) Current status on behavioral and biological markers of PTSD: a search for clarity in a conflicting literature. Neurosci Biobehav Rev 37:860-895

Publisher's note Springer Nature remains neutral with regard to jurisdictional claims in published maps and institutional affiliations. 